\title{
Effects of Proteasome Inhibitors on the Nucleolar Size of Porcine Oocytes
}

\author{
Mayumi JITSUKAWA'), Hirohisa KYOGOKU1), Sugako OGUSHI ${ }^{2,3)}$ and Takashi MIYANO') \\ 1) Graduate School of Agricultural Science, Kobe University, Kobe 657-8501, Japan \\ 2) The Young Researcher Development Center (Hakubi Center), Kyoto University, Kyoto 606-8302, Japan \\ 3) Department of Anatomy and Cell Biology, Graduate School of Medicine, Kyoto University, Kyoto 606-8315, Japan
}

\begin{abstract}
During the final stage of oocyte growth, the morphology of the oocyte nucleoli changes into a compact structure. The objective of this study was to determine the involvement of the proteasome, which is a large protein complex responsible for degrading intracellular proteins, in the nucleolar compaction. The mean nucleolar diameter of growing porcine oocytes (about $100 \mu \mathrm{m}$ in diameter) was larger than that of fully grown $(120 \mu \mathrm{m})$ oocytes $(15.5 \pm$ $0.3 v s .13 .2 \pm 0.1 \mu \mathrm{m}, \mathrm{P}<0.05)$. When fully grown oocytes were treated with proteasome inhibitors, MG132 (10 and 20 $\mu \mathrm{M})$ and lactacystin $(100$ and $200 \mu \mathrm{M})$, the nucleolar diameter significantly increased from $12.9 \mu \mathrm{m}$ to $14.9-16.1 \mu \mathrm{m}$. In contrast, transcription inhibitors, actinomycin $\mathrm{D}(0.8-8 \mu \mathrm{M})$ and $\alpha$-amanitin $(10-100 \mu \mathrm{M})$ reduced the nucleolar diameter of growing oocytes to $9.4-12.4 \mu \mathrm{m}$. MG132 partially prevented this reduction in nucleolar diameter. These results suggest that the proteasome regulates the nucleolar size in porcine oocytes perhaps through the degradation of nucleolar proteins.
\end{abstract} Key words: Lactacystin, MG132, Nucleolus, Oocyte, Proteasome inhibitor

(J. Reprod. Dev. 58: 162-166, 2012)

M ammalian oocytes grow and develop maturation and fertilizing ability during follicular development in the ovary. In the pig, oocytes with a diameter of $30 \mu \mathrm{m}$ in primordial follicles grow to a final size of $120 \mu \mathrm{m}$, while the follicles develop into antral follicles [1]. During the growth phase, oocytes actively synthesize RNAs and proteins, and oocyte nucleoli are intensively engaged in ribosomal RNA (rRNA) synthesis. As the oocytes approach their fully grown size, RNA synthetic activity decreases, and coincidently, the morphology of the nucleoli changes to a compact structure. Such nucleolar compaction has been described in various mammalian species including the mouse [2], rat [3, 4], cow [5] and pig [6]. In addition, it has been known that an RNA synthesis inhibitor (transcription inhibitor), actinomycin D, induces nucleolar compaction in growing oocytes collected from early antral follicles [6-8].

Nucleoli of somatic cells and growing oocytes in mammals are engaged in the transcription of ribosomal genes, pre-rRNA processing and assembly of preribosomal particles [9, 10]. Ribosome biogenesis is regulated by the transcription of ribosomal genes as well as posttranslational modifications including phosphorylation, methylation and acetylation of nucleolar-related proteins [11]. Moreover, ubiquitylation has recently been suggested to be involved in the ribosomal biogenesis in somatic cells. Stavreva et al. [12] examined the role of the ubiquitin-proteasome system in ribosome biogenesis using a proteasome inhibitor, MG132 (carbobenzoxy-Lleucyl-L-leucyl-L-leucinal), and found that the inhibitor induced

Received: September 28, 2011

Accepted: October 25, 2011

Published online in J-STAGE: November 16, 2011

(C2012 by the Society for Reproduction and Development

Correspondence: T. MIYANO (e-mail: miyano@kobe-u.ac.jp) drastic changes in nucleolar architecture. Proteasome is a large protein complex responsible for degrading intracellular proteins. Protein degradation through the ubiquitin-proteasome system is the major pathway of nonlysosomal proteolysis and plays crucial roles in cellular events such as the cell cycle, signal transduction, maintenance of proper protein folding and gene expression [13, 14].

We hypothesized that protein degradation through the ubiquitinproteasome system is involved in the morphological change of the oocyte nucleolus during the final stage of oocyte growth. After morphometric analysis of nucleoli in growing and fully grown oocytes collected from pig ovaries, we examined the effects of two kinds of proteasome inhibitor, MG132 and lactacystin, on the nucleolar morphology of fully grown oocytes. Furthermore, growing oocytes were treated with transcription inhibitors, actinomycin D and $\alpha$-amanitin, to induce nucleolar compaction, and the effects of proteasome inhibition on the compaction were examined.

Growing and fully grown porcine oocytes were collected from early antral follicles $0.6-1.0 \mathrm{~mm}$ diameter and large antral follicles $4.0-6.0 \mathrm{~mm}$ in diameter, respectively. The mean diameters of growing and fully grown oocytes were $97.4 \pm 0.6 \mu \mathrm{m}(\mathrm{n}=32)$ and $119.2 \pm 0.4 \mu \mathrm{m}(\mathrm{n}=44, \mathrm{P}<0.05)$, respectively. Since oocyte cytoplasm contains a number of lipid droplets, which often obscure the nucleoli, oocytes were centrifuged before measurement of nucleolar diameters. Both growing and fully grown oocytes had a large nucleus (germinal vesicle: GV) containing a definite nucleolus (Figs. 1A and 1B), although fully grown oocytes had a compact homogeneous nucleolus that looked like a polished glass bead. Since cytoplasmic lipid droplets still obscured the nucleoli in some centrifuged oocytes, measurement was performed on oocytes whose nucleoli could be clearly observed. The mean diameter of the nucleoli in growing oocytes was $15.5 \pm 0.3 \mu \mathrm{m}(\mathrm{n}=28)$, and that of fully grown oocytes was $13.2 \pm 0.1 \mu \mathrm{m}(\mathrm{n}=38, \mathrm{P}<0.05)$. These 


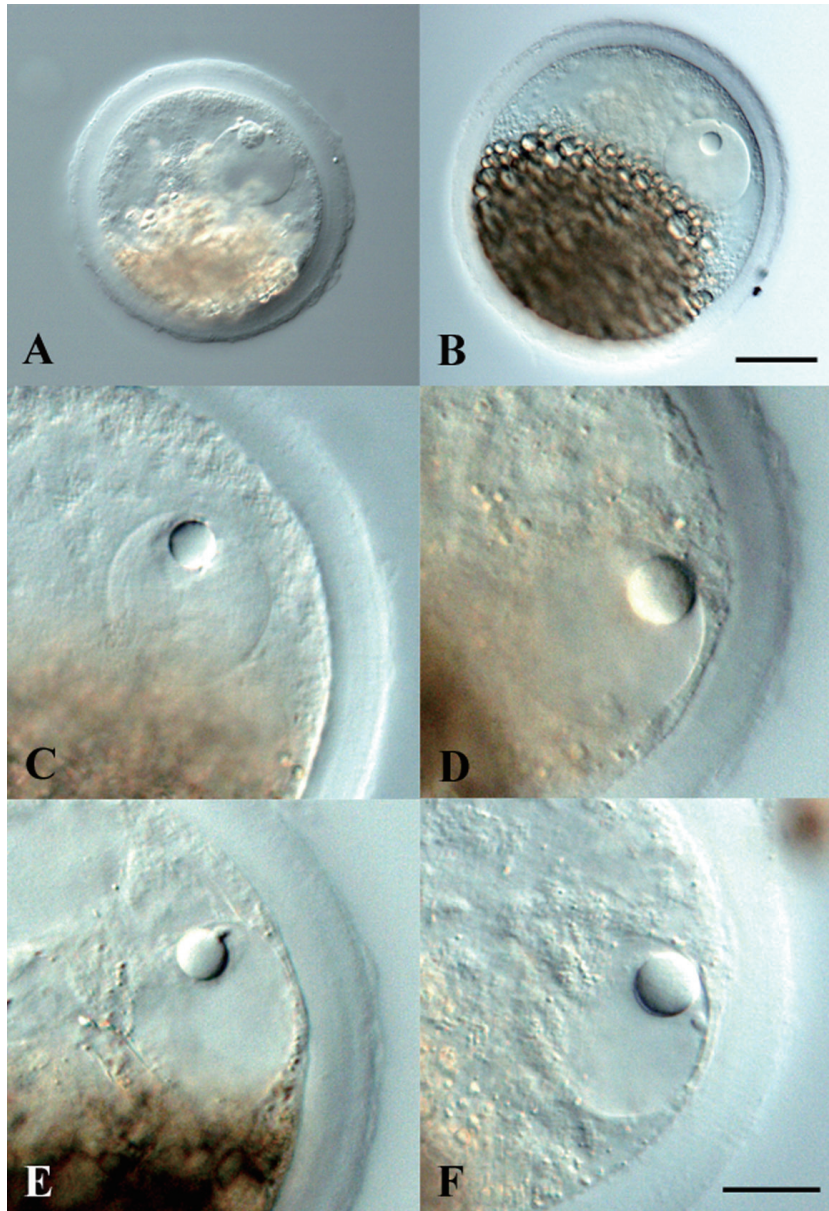

values show that the nucleolar diameter and volume decreased to $85 \%$ and $60 \%$, respectively, as the oocytes grew from 100 to $120 \mu \mathrm{m}$.

In the first experiment, fully grown oocytes were treated with two kinds of proteasome inhibitor. Cumulus-oocyte complexes containing fully grown oocytes were cultured in medium supplemented with MG132 $(2,10$ or $20 \mu \mathrm{M})$ or lactacystin $(10,100$ or 200 $\mu \mathrm{M})$ for $24 \mathrm{~h}$. After culture, most of the oocytes were at the GV stage and had a nucleolus (Figs. 1C-1F). However, the nucleolar diameters of MG132- and lactacystin-treated oocytes significantly increased in dose-dependent manners (Table 1). At the higher doses of both inhibitors, the nucleolar diameter increased to approximately $115 \%$, and the volume increased to $140 \%$ or more. A similar increase in nucleolar diameter was observed in denuded oocytes, although an increased number of degenerated oocytes made the results unclear (data not shown).

In the second experiment, cumulus-oocyte complexes containing growing oocytes were cultured with transcription inhibitors, actinomycin $\mathrm{D}(0.8,4$ or $8 \mu \mathrm{M})$ or $\alpha$-amanitin $(10,50$ or $100 \mu \mathrm{M})$, for $24 \mathrm{~h}$. The treatment caused the oocyte nucleoli to become compacted, whereas the control oocytes had as large a nucleolus as before culture (Figs. 2A-2C). Similar nucleolar compaction

Fig. 1. Differential interference contrast images of growing (A) and fully grown (B) porcine oocytes after centrifugation. Aggregations of lipid droplets like bubbles were located at the bottom of the oocytes, and nuclei (GVs) containing a nucleolus were located at the opposite side. After fully grown oocytes were treated with proteasome inhibitors, MG132 (D) or lactacystin (F), nucleoli increased in size. Control oocytes were cultured in the basal medium supplemented with $0.5 \%$ (v/v) DMSO for the MG132 group (C) or with $2 \mathrm{mM}$ dbcAMP for the lactacystin group (E). The bars are $40 \mu \mathrm{m}$ in $\mathrm{A}$ and $\mathrm{B}$ and $20 \mu \mathrm{m}$ in $\mathrm{C}-\mathrm{F}$.

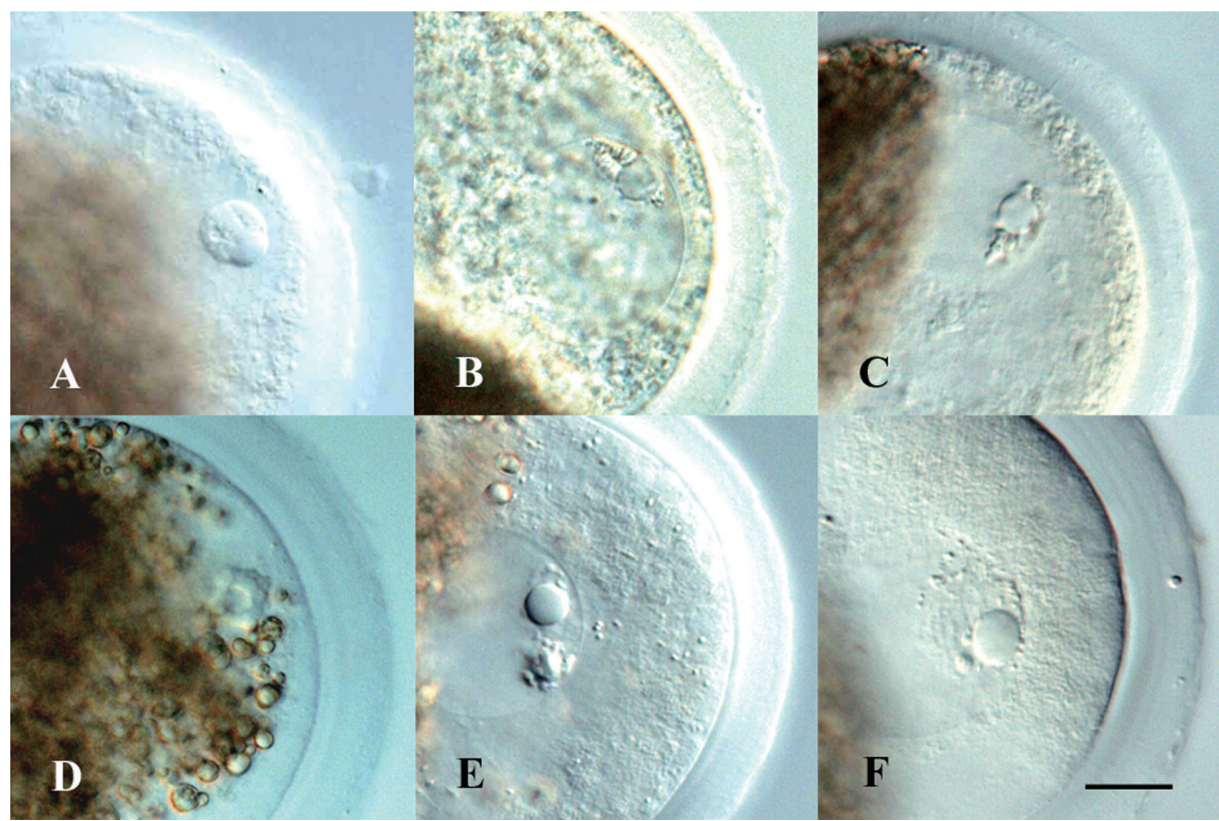

Fig. 2. Growing porcine oocytes were treated with transcription and proteasome inhibitors: $4 \mu \mathrm{M}$ actinomycin D (B); $50 \mu \mathrm{M} \alpha$-amanitin (C); $20 \mu \mathrm{M}$ MG132 (D); $0.8 \mu \mathrm{M}$ actinomycin D and $20 \mu \mathrm{M}$ MG132 (E); and $10 \mu \mathrm{M} \alpha$-amanitin and $20 \mu \mathrm{M}$ MG132 (F). Control oocytes were cultured in the basal medium supplemented with $1.0 \%$ (v/v) DMSO (A). The bar is $20 \mu \mathrm{m}$. 
Table 1. Effects of proteasome inhibitors on the nucleolar diameters of fully grown porcine oocytes

\begin{tabular}{lcccc}
\hline Proteasome inhibitor $(\mu \mathrm{M})$ & $\begin{array}{c}\text { Duration of } \\
\text { culture }(\mathrm{h})\end{array}$ & $\begin{array}{c}\text { No. of oocytes } \\
\text { examined }\end{array}$ & $\begin{array}{c}\text { Diameter of nucleolus } \\
(\mu \mathrm{m})^{*}\end{array}$ \\
\hline Before culture & - & 0 & 29 & $12.9 \pm 0.1^{\mathrm{a}}$ \\
MG132 & $0^{* *}$ & 24 & 31 & $13.0 \pm 0.2^{\mathrm{a}}$ \\
& 2 & 24 & 49 & $13.4 \pm 0.2^{\mathrm{ab}}$ \\
& 10 & 24 & 32 & $15.4 \pm 0.2^{\mathrm{c}}$ \\
Lactacystin & 20 & 24 & 29 & $16.1 \pm 0.2^{\mathrm{c}}$ \\
& $0^{* * *}$ & 24 & 31 & $13.3 \pm 0.1^{\mathrm{a}}$ \\
& 10 & 24 & 36 & $12.6 \pm 0.1^{\mathrm{a}}$ \\
& 100 & 24 & 38 & $14.9 \pm 0.1^{\mathrm{b}}$ \\
\hline
\end{tabular}

Cumulus-oocyte complexes containing fully grown oocytes were collected from large antral follicles $4.0-6.0 \mathrm{~mm}$ in diameter. After culture with proteasome inhibitors, oocytes were denuded, centrifuged and fixed to measure the nucleolar diameters. Diameters of nucleoli, which were clearly observed under a differential interference microscope, were measured. * Values are means \pm SEM. $* *$ Oocytes were treated with $0.5 \%(\mathrm{v} / \mathrm{v})$ DMSO. *** Oocytes were treated with $2 \mathrm{mM}$ dbcAMP. ${ }^{a-c}$ Values with different superscripts in the same column differ significantly $(\mathrm{P}<0.05)$.

Table 2. Effects of transcription inhibitors on the nucleolar diameters of growing porcine oocytes

\begin{tabular}{lccccc}
\hline \multicolumn{2}{c}{ Transcription inhibitor $(\mu \mathrm{M})$} & MG132 $(\mu \mathrm{M})$ & $\begin{array}{c}\text { Duration of } \\
\text { culture }(\mathrm{h})\end{array}$ & $\begin{array}{c}\text { No. of oocytes } \\
\text { examined }\end{array}$ & $\begin{array}{c}\text { Diameter of nucleolus } \\
(\mu \mathrm{m})^{*}\end{array}$ \\
\hline Before culture & - & - & 0 & 37 & $15.0^{2} \pm 0.4^{\mathrm{a}}$ \\
Cultured control ** & 0 & 0 & 24 & 36 & $15.1 \pm 0.2^{\mathrm{a}}$ \\
Actinomycin D & 0 & 20 & 24 & 31 & $15.7^{\mathrm{a}} \pm 0.2^{\mathrm{a}}$ \\
& 0.8 & 0 & 24 & 34 & $10.6 \pm 0.2^{\mathrm{b}}$ \\
& 4 & 0 & 24 & 24 & $9.4^{\mathrm{a}} \pm 0.2^{\mathrm{c}}$ \\
& 8 & 0 & 24 & 20 & $10.0 \pm 0.4^{\mathrm{bc}}$ \\
a-amanitin & 0.8 & 20 & 24 & 30 & $13.0 \pm 0.2^{\mathrm{d}}$ \\
& 10 & 0 & 24 & 35 & $12.4^{\mathrm{a}} \pm 0.2^{\mathrm{e}}$ \\
& 50 & 0 & 24 & 26 & $11.8 \pm 0.2^{\mathrm{f}}$ \\
& 100 & 0 & 24 & 28 & $11.6 \pm 0.2^{\mathrm{f}}$ \\
& 10 & 20 & 24 & 29 & $13.5 \pm 0.2^{\mathrm{d}}$ \\
\hline
\end{tabular}

Cumulus-oocyte complexes containing growing oocytes were collected from early antral follicles $0.6-1.0 \mathrm{~mm}$ in diameter. After culture with transcription inhibitors, oocytes were denuded, centrifuged and fixed to measure the nucleolar diameters. Diameters of nucleoli, which were clearly observed under a differential interference microscope, were measured. * Values are means \pm SEM. ** Oocytes were treated with $1.0 \%(\mathrm{v} / \mathrm{v})$ DMSO. ${ }^{\mathrm{a}-\mathrm{f}}$ Values with different superscripts in the same column differ significantly $(\mathrm{P}<0.05)$.

was induced in denuded oocytes, but the number of degenerated oocytes increased (data not shown). The mean nucleolar diameter of growing oocytes did not change in the cultured control, whereas the nucleolar diameters of oocytes treated with actinomycin D or $\alpha$-amanitin significantly decreased to $9.4-12.4 \mu \mathrm{m}$ (Table 2). The effects of MG132 on actinomycin D- or $\alpha$-amanitin-induced nucleolar compaction were examined. The nucleolar morphology of MG132-treated growing oocytes was similar to the control oocytes (Fig. 2D). Although the oocytes treated with actinomycin D or $\alpha$-amanitin in combination with MG132 had a compacted nucleolus (Figs. 2E and 2F), the nucleolar diameters were larger than those in the oocytes treated with transcription inhibitor alone (Table 2).

The present study shows that nucleoli of porcine oocytes decrease in size as a result of nucleolar compaction during the final stage of oocyte growth from 100 to $120 \mu \mathrm{m}$ in the ovary. The compaction might be due to several physiological phenomena such as retraction of intranucleolar chromatin [6], exclusion of nucleolar proteins from the nucleolus to the nucleoplasm [15] and nucleolar protein degradation as suggested here. In somatic cells, a number of intracellular proteins are continuously synthesized and subsequently degraded, and such a continuous turnover of proteins is required for the maintenance of cellular structure and functions [16]. Protein degradation is mediated partially by the ubiquitinproteasome pathway, which plays important roles in various cellular processes including the cell cycle, cell division, differentiation and development, DNA repair, biogenesis of organelles and apoptosis and so on $[14,17]$. MG132 and lactacystin inhibit the proteasome specifically in mammalian somatic cells [18]. Based on the effects of the proteasome inhibitors, it has been suggested that the ubiquitin-proteasome system plays important roles in maturation and fertilization of oocytes [19,20] and zygotic gene activation of embryos [21]. 
Besides these roles, it has been suggested here that proteasomedependent protein degradation regulates the nucleolar size of oocytes. In the present study, two kinds of proteasome inhibitor increased the nucleolar size of fully grown porcine oocytes. The results are probably not caused by the deleterious effect of the inhibitors because oocytes treated with MG132 for $24 \mathrm{~h}$ maintained maturation competence after washing the inhibitor off the oocytes in our preliminary experiment. Furthermore, MG132 partially prevented transcription inhibitor-induced nucleolar size reduction in growing oocytes. The results suggest that the nucleolar compaction during oocyte growth is associated with degradation of nucleolar proteins by the proteasome. The effect of MG132 on the nucleolar size was stronger in fully grown oocytes than in growing oocytes. The reason for this is unclear; however, it is possible that the degradation of nucleolar proteins might be promoted in fully grown oocytes perhaps by higher proteasome activity or increased ubiquitination of nucleolar proteins. This possibility and ubiquitination of proteins in oocyte nucleoli require further study. It has been reported in somatic cells that MG132 induces accumulation of proteasomes, PML (promyelocytic leukemia gene product), Sp100 and SUMO-1 in the nucleoli, and it has been suggested that the nucleolus may have a function in the regulation of proteasomal protein degradation [22].

Transcription inhibitors, actinomycin D and $\alpha$-amanitin, caused nucleolar compaction in growing porcine oocytes, as previously reported by Crozet [7]. Although the transcription inhibitor-induced nucleolar compaction mimics the compaction during oocyte growth in vivo, the reason why the decreased transcriptional activity leads to the nucleolar morphological change is not yet understood. Nonetheless, the results in the present study suggest that the transcription inhibitor-induced nucleolar compaction is associated with degradation of nucleolar proteins by the proteasome. Since MG132 causes accumulation of numerous proteasome-target proteins into nucleoli in somatic cells without inhibition of their transcriptional activity [23], it cannot be assumed that the MG132 affected the oocyte nucleolar size via the effect on the transcriptional activity. It is thought that in the ovary, some unknown factor triggers the downregulation of RNA synthetic activity in growing oocytes, whose nucleoli in turn become compacted through the retraction of intranucleolar chromatin, exclusion of nucleolar proteins from the nucleolus and degradation of nucleolar proteins by the ubiquitin-proteasome system.

\section{Methods}

\section{Oocyte collection and culture}

Porcine ovaries were obtained from prepubertal gilts at a local slaughterhouse. After three washes in Dulbecco's phosphatebuffered saline (PBS) containing $0.1 \%(\mathrm{w} / \mathrm{v})$ polyvinyl alcohol (PVA; Sigma-Aldrich, St. Louis, MO, USA), intact healthy early antral follicles $0.6-1.0 \mathrm{~mm}$ in diameter and large antral follicles $4.0-6.0 \mathrm{~mm}$ in diameter were dissected from ovaries. Ovarian cortical slices $(1-1.5 \mathrm{~mm})$ were cut from the ovarian surface by using a surgical blade (No. 21; Keisei Medical Industrial, Tokyo, Japan), and early antral follicles were dissected in PBS-PVA using a surgical blade (No. 21) and a pair of forceps under a dissecting microscope. Large antral follicles of 4.0-6.0 $\mathrm{mm}$ in diameter were dissected from ovaries by using two surgical blades (No. 11; Keisei Medical Industrial) in PBS-PVA. Collected follicles were opened in 25 mM HEPES-buffered medium 199 (HEPES-M199; Nissui Pharmaceutical, Tokyo, Japan) containing 0.1\% PVA, $10 \mathrm{mM}$ sodium bicarbonate and $0.08 \mathrm{mg} / \mathrm{ml}$ kanamycin sulphate (Sigma-Aldrich), and cumulus-oocyte complexes (COCs) were isolated from the follicles under a dissecting microscope.

Following three washes with HEPES-M199, groups of 10-15 COCs were cultured in $500 \mu 1$ of basal medium supplemented with inhibitors in a 4-well multidish (Nunclon 4 Well Multidish; Sigma-Aldrich) in an atmosphere of $5 \% \mathrm{CO}_{2}$ in humidified air at $38.5 \mathrm{C}$. The basal medium was bicarbonate-buffered medium 199 (TCM-199) supplemented with 10\% (v/v) fetal calf serum (FCS; ICN Biomedicals, Aurora, OH, USA), $0.1 \mathrm{mg} / \mathrm{ml}$ sodium pyruvate, $0.08 \mathrm{mg} / \mathrm{ml}$ kanamycin sulphate and $25 \mathrm{mM}$ sodium bicarbonate. COCs containing fully grown oocytes were cultured in the medium supplemented with MG132 $(2,10$ or $20 \mu \mathrm{M}$, Calbiochem, San Diego, CA, USA) or lactacystin (10, 100 or 200 $\mu \mathrm{M}$, Calbiochem) for $24 \mathrm{~h}$. In the solvent control group, oocytes were cultured with $0.5 \%$ (v/v) dimethyl sulfoxide (DMSO; Wako Pure Chemical Industries, Osaka, Japan) for $24 \mathrm{~h}$. For lactacystin treatment, $2 \mathrm{mM}$ dibutyryl adenosine 3',5'-cyclic monophosphate sodium salt (dbcAMP, Sigma-Aldrich) was added to the culture medium to suppress the spontaneous meiotic resumption of oocytes.

COCs containing growing oocytes were cultured in the medium supplemented with actinomycin D $(0.8,4$ or $8 \mu \mathrm{M}$, Sigma-Aldrich) or $\alpha$-amanitin (10, 50 or $100 \mu \mathrm{M}$, Sigma-Aldrich) for $24 \mathrm{~h}$. Some of the COCs were cultured in the basal medium supplemented with $0.8 \mu \mathrm{M}$ actinomycin $\mathrm{D}$ or $10 \mu \mathrm{M} \alpha$-amanitin for $24 \mathrm{~h}$ in combination with $20 \mu \mathrm{M}$ MG132. In the solvent control group, oocytes were cultured with $1.0 \%$ (v/v) DMSO for $24 \mathrm{~h}$. Actinomycin D and MG132 were dissolved in DMSO to prepare stock solutions and then kept at $-20 \mathrm{C}$. Alpha-amanitin and lactacystin were dissolved in TCM-199 to prepare stock solutions and kept at -20 C until use.

\section{Measurement of diameters of oocytes and nucleoli}

After culture, cumulus cells were removed from the oocytes by gentle pipetting with a small-bore pipette in HEPES-M199. Oocytes were transferred into prewarmed HEPES-M199 drops $(15 \mu 1)$ individually, and their diameters (without zona pellucida) were measured to the nearest $1 \mu \mathrm{m}$ with an ocular micrometer attached to an inverted phase-contrast microscope (OSM-4; Olympus Optical, Tokyo, Japan). For measurement of nucleolar diameters, oocytes were incubated in prewarmed HEPES-M199 containing $7.5 \mu \mathrm{g} / \mathrm{ml}$ cytochalasin B (Sigma-Aldrich) for $10 \mathrm{~min}$ in an atmosphere of $5 \% \mathrm{CO}_{2}$ in humidified air at $38.5 \mathrm{C}$. Then growing oocytes and fully grown oocytes were centrifuged at 3,000 $\mathrm{g}$ and $4,000 \mathrm{~g}$ for $10 \mathrm{~min}$, respectively. Then the oocytes were washed with PBS-PVA several times and fixed with PBS-PVA containing $4 \%$ (w/v) paraformaldehyde (Wako Pure Chemical Industries) for $40 \mathrm{~min}$. After fixation, the oocytes were washed with PBS-PVA three times, mounted on slides with PBS-PVA, and observed by a differential interference microscope (BX51; Olympus Optical). Photos of oocytes and an objective micrometer were taken at the same magnification by Viewfinder Life (Pixela, Osaka, Japan), and 
the diameters of nucleoli were measured. Each culture experiment was conducted at least three times. Statistical differences in the mean $( \pm$ SEM) diameters of oocytes and nucleoli were analyzed by the Student's $t$-test. Values of $\mathrm{P}<0.05$ were considered to indicate statistical significance.

\section{Acknowledgments}

The authors would like to thank the staff of the Kobe Meat Inspection Office (Kobe, Japan) for supplying porcine ovaries. This work was supported in part by a Grant-in-Aid for Scientific Research to TM (23658226) and a Research Fellowship for Young Scientists to HK from the Japan Society for the Promotion of Science.

\section{References}

1. Miyano T, Manabe N. Oocyte growth and acquisition of meiotic competence. Soc Reprod Fertil Suppl 2007; 63: 531-538. [Medline]

2. Chouinard LA. A light- and electron-microscope study of the nucleolus during growth of the oocyte in the prepubertal mouse. J Cell Sci 1971; 9: 637-663. [Medline]

3. Takeuchi IK. Electron-microscopic study of silver staining of nucleoli in growing oocytes of rat ovaries. Cell Tissue Res 1984; 236: 249-255. [Medline] [CrossRef]

4. Antoine N, Lepoint A, Baeckeland E, Goessens G. Evolution of the rat oocyte nucleolus during follicular growth. Biol Cell 1987; 59: 107-112. [Medline]

5. Crozet N, Kanka J, Motlik J, Fulka J. Nucleolar fine structure and RNA synthesis in bovine oocytes from antral follicles. Gamete Res 1986; 14: 65-73. [CrossRef]

6. Crozet N. Nucleolar structure and RNA synthesis in mammalian oocytes. J Reprod Fertil Suppl 1989; 38: 9-16. [Medline]

7. Crozet N. Effects of actinomycin D and cycloheximide on the nucleolar ultrastructure of porcine oocytes. Biol Cell 1983; 48: 25-29. [Medline]

8. Kyogoku H, Ogushi S, Miyano T, Fulka J Jr. Nucleoli from growing oocytes inhibit the maturation of enucleolated, full-grown oocytes in the pig. Mol Reprod Dev 2011; 78: 426-435. [Medline] [CrossRef]

9. Olson MO, Hingorani K, Szebeni A. Conventional and nonconventional roles of the nucleolus. Int Rev Cytol 2002; 219: 199-266. [Medline] [CrossRef]
10. Olson MO, Dundr M. The moving parts of the nucleolus. Histochem Cell Biol 2005; 123: 203-216. [Medline] [CrossRef]

11. Leary DJ, Huang S. Regulation of ribosome biogenesis within the nucleolus. FEBS Lett 2001; 509: 145-150. [Medline] [CrossRef]

12. Stavreva DA, Kawasaki M, Dundr M, Koberna K, Müller WG, Tsujimura-Takahashi T, Komatsu W, Hayano T, Isobe T, Raska I, Misteli T, Takahashi N, McNally JG. Potential roles for ubiquitin and the proteasome during ribosome biogenesis. Mol Cell Biol 2006; 26: 5131-5145. [Medline] [CrossRef]

13. Hershko A, Ciechanover A. The ubiquitin system. Annu Rev Biochem 1998; 67: 425-479. [Medline] [CrossRef]

14. Ciechanover A. Proteolysis: from the lysosome to ubiquitin and the proteasome. Nat Rev Mol Cell Biol 2005; 6: 79-87. [Medline] [CrossRef]

15. Bjerregaard B, Wrenzycki C, Philimonenko VV, Hozak P, Laurincik J, Niemann H, Motlik J, Maddox-Hyttel P. Regulation of ribosomal RNA synthesis during the final phases of porcine oocyte growth. Biol Reprod 2004; 70: 925-935. [Medline] [CrossRef]

16. Martinez-Vicente M, Sovak G, Cuervo AM. Protein degradation and aging. Exp Gerontol 2005; 40: 622-633. [Medline] [CrossRef]

17. Ciechanover A. The ubiquitin-proteasome pathway: on protein death and cell life. EMBO J 1998; 17: 7151-7160. [Medline] [CrossRef]

18. Lee DH, Goldberg AL. Proteasome inhibitors: valuable new tools for cell biologists. Trends Cell Biol 1998; 8: 397-403. [Medline] [CrossRef]

19. Josefsberg LB, Galiani D, Dantes A, Amsterdam A, Dekel N. The proteasome is involved in the first metaphase-to-anaphase transition of meiosis in rat oocytes. Biol Reprod 2000; 62: 1270-1277. [Medline] [CrossRef]

20. Huo LJ, Fan HY, Zhong ZS, Chen DY, Schatten H, Sun QY. Ubiquitin-proteasome pathway modulates mouse oocyte meiotic maturation and fertilization via regulation of MAPK cascade and cyclin B1 degradation. Mech Dev 2004; 121: 1275-1287. [Medline] [CrossRef]

21. Shin SW, Tokoro M, Nishikawa S, Lee HH, Hatanaka Y, Nishihara T, Amano T, Anzai M, Kato H, Mitani T, Kishigami S, Saeki K, Hosoi Y, Iritani A, Matsumoto K. Inhibition of the ubiquitin-proteasome system leads to delay of the onset of ZGA gene expression. J Reprod Dev 2010; 56: 655-663. [Medline] [CrossRef]

22. Mattsson K, Pokrovskaja K, Kiss C, Klein G, Szekely L. Proteins associated with the promyelocytic leukemia gene product (PML)-containing nuclear body move to the nucleolus upon inhibition of proteasome-dependent protein degradation. Proc Natl Acad Sci USA 2001; 98: 1012-1017. [Medline] [CrossRef]

23. Latonen L, Moore HM, Bai B, Jäämaa S, Laiho M. Proteasome inhibitors induce nucleolar aggregation of proteasome target proteins and polyadenylated RNA by altering ubiquitin availability. Oncogene 2011; 30: 790-805. [Medline] [CrossRef] 